\title{
Inserção profissional e formação continuada de egressas/os de graduação em Serviço Social
}

\author{
Professional insertion and continuing education of graduates in Social Work
}

\author{
Cristina Kologeski Fraga* \\ Cristina Maria Pinto Albuquerque**
}

\begin{abstract}
Resumo
O objetivo deste artigo foi analisar aspectos da inserção profissional e/ou formação continuada de egressos de um curso de bacharelado em Serviço Social da Universidade Federal de Santa Maria (UFSM). Participaram 82 egressas/os concluintes entre o período de 2014 a 2018, que responderam às questões de um questionário online, especificamente elaborado e validado à pesquisa, buscando informações concernentes à sua inserção profissional e/ou formação continuada. Também foram realizadas cinco entrevistas com formadas/os em Serviço Social da UFSM. De maneira geral, constatouse que a maioria das/os formadas/os estava inserida no mercado de trabalho, predominantemente fora de sua área de formação. Entre aquelas/es que estavam trabalhando na área, verificou-se, além da baixa remuneração, também o descumprimento da lei № 12.317/ 2010 que dispõe sobre a jornada de trabalho das/os assistentes sociais, prevista para o máximo de 30 horas semanais. Em contrapartida, percebeu-se como perspectivas e possibilidades, a realização de atividades de formação continuada em Serviço Social, com destaque para cursos de especialização, mestrado e doutorado. As evidências encontradas podem fornecer indicadores acerca da qualidade do ensino em Serviço Social da UFSM, bem como contribuir para o aprimoramento contínuo da formação inicial oferecida aos estudantes deste curso.
\end{abstract}

Palavras-chave: Formação continuada. Mercado de trabalho. Egressos. Universidade. Serviço Social.

\section{Abstract}

The aim of the study of this article was to analyze aspects of the professional insertion and / or continuous formation of graduates of a bachelor degree course in Social Work at the Federal University of Santa Maria (UFSM). Eighty-two graduates concluding between the period of 2014 to 2018 participated, who answered the questions of an online questionnaire, specifically designed and validated for the research, seeking information regarding their professional insertion and / or continuing education. There were also five interviews with graduates in Social Work at UFSM. In general, it was found that most of the graduates were inserted in the labor market, predominantly outside their area of training. Among those who were working in the area, in addition to the low remuneration, there was also the non-compliance with Law No. 12.317 / 2010, which provides for the working hours of social workers, scheduled for a maximum of 30 hours per week. On the other hand, it was perceived as perspectives and possibilities, the realization of continuing education activities in Social Work, with emphasis on specialization courses, Master and Doctorate. The evidence found can provide indicators about the quality of UFSM's teaching in Social Work, as well as contribute to the continuous improvement of the initial training offered to students of this course.

Keywords: Continuing education. Labor market. Graduates. University. Social work.

\footnotetext{
* Professora do Curso de Serviço Social da UFSM. Pós-Doutoranda de Serviço Social pela Faculdade de Psicologia e Ciências da Educação (FPCE) da Universidade de Coimbra, Portugal.

** Professora da Faculdade de Psicologia e de Ciências da Educação da Universidade de Coimbra, investigadora do Centro de Estudos Interdisciplinares do Século XX (CEIS20) da Universidade de Coimbra. Vice-reitora da Universidade de Coimbra.
} 


\section{Considerações iniciais}

O contexto atual, caracterizado por acentuados e velozes avanços tecnológicos, tem implicado em transformações profundas nas mais diferentes searas da vida humana, dentre as quais pode-se destacar o mercado de trabalho e, por conseguinte, a formação profissional. A denominada sociedade da informação, na qual os dados estão se tornando o mais importante capital do mundo, tem muitos impactos positivos e facilitadores da vida social, contudo também não é possível ignorar que traz incertezas e instabilidade na esfera profissional, tendo em vista que as oportunidades e as novas modalidades de inserção contrastam com o desemprego crescente em vários campos de atuação. Essa volatilidade do mercado implica, também, no surgimento de novos espaços de inserção e na necessidade imperativa de profissionais atentos às respectivas exigências.

O Serviço Social, por exemplo, destaca-se como uma área profissional de ampla atuação. A/o assistente social exerce sua atividade profissional em diversos espaços, âmbitos, áreas, segmentos populacionais (crianças e adolescentes, idosos, pessoas com deficiência, família) e em diferentes setores (seguridade social: saúde, previdência social, assistência social, educação, trabalho, habitação e na questão agrária). Dessa multiplicidade de atuação, advém ainda uma variedade de processos de trabalho, o que exige desse profissional, conforme abordado em Fraga (2010), um arsenal de conhecimentos variados e uma disposição constante em se aprimorar.

No que tange aos espaços sócio-ocupacionais, a/o assistente social pode atuar em entidades públicas, tais como: prefeituras, judiciário, Ministério Público, Instituto Nacional de Seguro Social (INSS), escolas, albergues, abrigos, sistema carcerário (presídios e penitenciárias), Fundação de Atendimento Socioeducativo (FASE), hospitais; em entidades privadas: empresas de serviços, de comércio, de indústria. No denominado terceiro setor, poderá atuar em entidades socioassistenciais, associações de moradores, organizações nãogovernamentais (ONGs). Além disso, poderá trabalhar também nas áreas de ensino e pesquisa, de maneira autônoma, com assessoria e consultoria em projetos de gestão e planejamento social. (FRAGA, 2010).

Mesmo com toda essa amplitude e variedade de espaços de atuação profissional, não se pode desconsiderar que as mudanças ocorridas no mercado de trabalho foram desfavoráveis a novos postos de trabalho e ampliação de vagas. Isso porque as/os assistentes sociais, como as demais pessoas que vivem do seu trabalho, experienciaram a retração de 
postos de trabalho, principalmente no setor público (campo mais tradicional), contrastando com o aumento de oportunidades em locais como organizações não-governamentais e terceiro setor (campos menos tradicionais ao Serviço Social).

A Medida Provisória (MP) no 905, publicada no Diário Oficial da União (DOU) em 11 de novembro de $2019^{1}$ é um exemplo que atinge as relações de trabalho da/o assistente social e aumenta a desproteção social das/os cidadãs/os brasileiras/os em virtude de que extingue o Serviço Social no Instituto Nacional do Seguro Social (INSS) e acaba com o único atendimento presencial ao qual usuárias/os têm acesso na autarquia, conforme nota do CFESS (2019), sob o título "Sem Serviço Social no INSS, quem perde é você! Sabe por quê?"

$\mathrm{Na}$ onda dos crescentes ataques às leis trabalhistas e à Previdência engendradas pelo governo Bolsonaro, a referida MP prevê - dentre outros prejuízos à população - que o Regime Geral de Previdência Social (RGPS), gerido nacionalmente pelo INSS e de responsabilidade da União, deixe de prestar o Serviço Social enquanto direito dos segurados e seus dependentes, além dos demais usuários do INSS em todo o país.

O Serviço Social do Instituto Nacional do Seguro Social (INSS) constitui-se, pois, em um atendimento efetivo para garantir os direitos e orientar o/a trabalhador/a, e seus familiares, em relação aos seus benefícios. Sendo assim, depreende-se que essa MP possui evidentemente o objetivo de dificultar o acesso das/os cidadãs/os aos benefícios previdenciários e assistenciais no Brasil. Conforme a nota do CFESS (2019), a MP 905/2019 extingue o Serviço Social bem como serviço no Regime Geral de Previdência Social, que é um direito do/a trabalhador/a brasileiro/a desde a década de 1940.

Apesar dessa significativa perda à categoria de assistentes sociais brasileiras/os, ainda é possível visualizar como perspectiva futura para a atuação na área de Serviço Social a recente aprovação da Lei 13.935 que garante os Serviços de Psicologia e Serviço Social nas escolas, uma reivindicação de longa data. Publicada em 12 de dezembro de 2019 no Diário

\footnotetext{
${ }^{1}$ Sobre essa Medida Provisória, sugere-se a leitura da reportagem de Claudia Dianni, intitulada "MP do Programa Verde Amarelo extingue serviço social do INSS", disponível no site do Correio Brasiliense. Segundo ela, no meio da MP 905, de incentivo à contratação de jovens, o dispositivo extingue atendimento pessoal feito por assistentes sociais nas agências do Instituto Nacional do Seguro Social. Ainda, segundo o Correio Brasiliense, em julho, o INSS divulgou que passou a atender 90 dos 96 serviços por meio do aplicativo e do site Meu INSS, ou pelo telefone 135. Segundo informou o INSS na época, com os serviços automatizados, não será preciso falar com um atendente, na maioria dos casos. No entanto, conforme dados da Pesquisa Nacional por Amostra de Domicílios (Pnad) (apud DIANNI, 2019), em 2016, 23,9 milhões de pessoas não se conectavam à internet por não saber usar a ferramenta e 63 milhões sequer estavam conectados. A medida afeta aproximadamente 1.600 profissionais assistentes sociais que serão transferidos para desempenhar outras funções.
} 
Oficial da União, a Lei 13.935 dispõe sobre a prestação de serviços de Psicologia e de Serviço Social nas redes públicas de educação básica. O texto da referida Lei prevê em seu art. 1ㅇque as redes públicas de educação básica contarão com serviços das áreas mencionadas para "[...] atender às necessidades e prioridades definidas pelas políticas de educação, por meio de equipes multiprofissionais" (BRASIL, 2019), que deverão desenvolver ações para a melhoria da qualidade do processo de ensino-aprendizagem. Os sistemas de ensino têm um ano para implementação e cumprimento da nova lei.

É possível reconhecer que, apesar de tantos retrocessos produzidos pelo governo brasileiro atual², a Lei 13.935 representa uma significativa conquista para a educação básica, para estudantes e suas famílias e, como não poderia deixar de ser, uma grande conquista para assistentes sociais e psicólogos/as.

Outro avanço importante do Serviço Social brasileiro refere-se à Política de Educação Permanente do Conjunto CFESS-CRESS que realça a dimensão da educação permanente enquanto instrumento de luta da categoria de assistentes sociais, sinaliza o panorama nacional da educação superior no Brasil e seus rebatimentos na formação desses profissionais e trata das diretrizes, objetivos e estratégias para a concretização da Política de Educação Permanente do Conjunto CFESS-CRESS (CFESS, 2012).

A Política de Educação Permanente mostra-se como um importante instrumento de luta da categoria diante dos riscos e desafios provocados pela velocidade crescente de mudanças na sociedade contemporânea. Revela-se, desse modo, como uma necessidade da busca incessante pelo aprimoramento das competências de intervenção profissional, de modo a garantir o que prevê o Código de Ética do Assistente Social, o compromisso com a qualidade dos serviços prestados à população usuária e com o aprimoramento intelectual, na perspectiva da competência profissional (CFESS, 2011).

É bem verdade que a tendência de ampliação na competitividade alude, fundamentalmente, ao desenvolvimento de ações que exigem uma busca constante por parte das/os assistentes sociais para qualificar suas competências à intervenção social.

A inquietação de compreender determinados aspectos da inserção profissional de egressas/os do curso de graduação em Serviço Social impulsionou esta investigação que foi

\footnotetext{
${ }^{2}$ Em que pese o governo Bolsonaro ter vetado a Lei 13.935 que garante os Serviços de Psicologia e Serviço Social nas escolas, a pressão dos conselhos de Serviço Social e de Psicologia além do apoio da sociedade motivaram o parlamento a aprovar essa lei.
} 
ao encontro das/os egressas/os desse curso e buscou saber por elas/eles mesmas/os a sua situação profissional após saída da Universidade. Nesse sentido, além de procurar saber quem eram, quantas/os eram, quantos anos possuíam, como se autodeclaravam em raça/cor, estado civil, ou seja, seu perfil, também procurou saber se tinham conseguido se inserir no mercado de trabalho, seja como assistente social, seja em outra área, bem como a remuneração recebida, a carga horária semanal e se tinham buscado aprimoramento profissional em cursos de formação continuada.

Considerando a relevância da formação continuada para alcançar maiores possibilidades no mercado de trabalho duramente competitivo dos tempos atuais, este estudo também preocupou-se em investigar com as/os egressas/os, seus investimentos em cursos de pós-graduação Lato e Stricto Sensu e todos os seus esforços de formação envidados após a graduação. Com base em Pinto, Barreiro e Silveira (2010) considera-se como ações de formação continuada: congressos, seminários, simpósios, colóquios, encontros, jornadas, ciclos de falas, palestras, grupos de pesquisa, grupos de estudos, grupos de formação, projetos de pesquisa, oficinas, cursos de extensão e/ou aperfeiçoamento sobre um conteúdo específico e/ou questões relacionadas ao Serviço Social efetuados na universidade e em outros espaços. Além dessas ações pontuais, são considerados os cursos de pós-graduação Lato Sensu, Pós-graduação Stricto Sensu (Mestrado e Doutorado) e processos permanentes realizados na universidade, com encontros regulares. Cada proposta, de acordo com suas características, propicia o atendimento a diferentes necessidades e interesses das/os profissionais, podendo contribuir como suporte importante à atuação da/o assistente social e ao seu desenvolvimento profissional.

Buscando contemplar esta preocupação com a formação continuada e com a inserção profissional, o presente estudo se propôs investigar a inserção no mercado de trabalho de egressas/os do curso de bacharelado em Serviço Social da Universidade Federal de Santa Maria, no Rio Grande do Sul.

\section{Construção Metodológica}


O estudo se caracteriza como um estudo analítico-crítico, pesquisa documental ${ }^{3}$ e também abordagem direta, por meio de entrevistas com as/os sujeitas/os. Caracteriza-se, metodologicamente, como uma pesquisa mista, considerando-se que é quanti-qualitativa, tendo como referência, em todo seu processo, o método crítico-dialético.

De acordo com Prates (2012), a caracterização de uma pesquisa como quantiqualitativa ou mista diverge dos estudos classificados como quantitativos e qualitativos, e deve valer-se de características de ambos, ainda que destaque um ou outro, conformando-se com outro tipo de estudo, com particularidades que emanam dos dois. Justamente por ressaltar a articulação de dados dos dois tipos, são mais coerentes com o método marxista de investigação, que observa essa relação como necessária.

Na perspectiva do uso articulado de dados quantitativos e qualitativos, como sugere Prates (2012), atribuindo igual relevância a ambos; destaca-se a expressão da voz dos sujeitos e a valorização não só de resultados, mas também do processo da investigação; da clareza de finalidade que a pesquisa teve, sendo seu objeto o curso público de Serviço Social da UFSM (instituído em 2010/2) e como sujeitas/os as/os egressas/os desse curso formadas/os desde sua primeira turma (2014/2) até a turma mais recente (2018/2).

A execução da pesquisa iniciou após a aprovação do projeto de pesquisa pelo Comitê de Ética em Pesquisa da UFSM (parecer no 3073703), quando então foram solicitadas à secretária do Curso de Serviço Social da UFSM informações relativas à totalidade de formadas/os, procedendo-se, assim, a pesquisa documental.

A coleta de dados inicial da pesquisa foi realizada no primeiro semestre de 2019 , na Universidade Federal de Santa Maria, interior do Rio Grande do Sul, Brasil. Assim sendo, foi analisada a relação entre a formação profissional dos/das egressos/as dos cursos de Serviço Social da UFSM e sua repercussão na inserção desses profissionais na formação continuada, com vistas a contribuir com o aprimoramento e qualidade desses espaços de formação acadêmica.

As/os egressas/os foram contatadas/os por meio de seus endereços eletrônicos, repassados pela coordenação do curso de Serviço Social da UFSM. Através do e-mail, as/os egressas/os receberam todas as informações sobre a procedência e os objetivos da pesquisa,

\footnotetext{
${ }^{3}$ No que concerne à pesquisa documental, Gil (2007) explica que se vale de materiais que não receberam ainda um tratamento analítico, por isso é uma fonte rica e estável de dados, já que os documentos subsistem com o passar do tempo.
} 
na forma de um Termo de Consentimento Livre e Esclarecido (TCLE). Em caso de concordância em participar da pesquisa, o questionário no qual constava o "link" da página eletrônica era disponibilizado para ser respondido.

Ainda referente à coleta de dados quantitativa, ressalta-se que foi utilizado um questionário online especialmente construído e validado para a presente investigação. Tal instrumento foi elaborado com o auxílio da ferramenta para a criação de formulários Google Docs. O questionário, composto por 35 questões (fechadas, abertas ou de múltipla escolha) relativas ao perfil das/dos assistente sociais, buscou reunir informações caracterizadoras das/os sujeitos da pesquisa, bem como investigou determinados aspectos relacionados à colocação profissional e, também, suas inserções em alguma atividade de formação continuada. A validação de conteúdo e a avaliação de nitidez de linguagem do questionário foram realizadas por dois mestrandos que aceitaram participar do teste piloto.

Posteriormente, foram selecionadas/os, intencionalmente, cinco egressas/os desse curso para as entrevistas. Essas/os aceitaram participar livremente da pesquisa e tiveram seus depoimentos $^{4}$ relacionados com a inserção no mercado de trabalho e/ou na formação continuada. As entrevistas foram guiadas por um roteiro com questões relativas, primeiramente, à caracterização das/dos assistentes sociais entrevistadas/os, tais como: idade, gênero, ano de conclusão do curso, se estava inserida/o no mercado de trabalho como assistente social, caso positivo, há quanto tempo, se estava colocada/o no mercado de trabalho em outra atividade e qual, a renda salarial líquida em salários mínimos, forma de inserção no mercado de trabalho (concurso público, contrato temporário/prestação de serviço, celetista ou por indicação), além de aspectos relativos ao local ou setor em que trabalhava, assim como, se havia realizado ou se estava realizando alguma capacitação profissional ou formação profissional continuada. Após, as questões versavam sobre a graduação e sua relação com o mercado de trabalho e com a formação continuada, buscando apreender a profundidade das experiências dos/as sujeitos/as da pesquisa, já que, de acordo com Minayo (2012, p. 21), a pesquisa qualitativa "[...] trabalha com o universo de significados, dos motivos, das aspirações, das crenças, dos valores e das atitudes."

A análise quantitativa foi realizada por meio de análise estatística, sendo que as informações coletadas foram organizadas para que fosse possível evidenciar informações

\footnotetext{
${ }^{4}$ As entrevistas ocorreram no Campus da UFSM, na sala do núcleo de Estudos, Pesquisa e Extensão em Violência e Serviço Social/Nepevis.
} 
relevantes, em termos objetivos da pesquisa, passando pela distribuição de frequências, conforme Barbetta (2006). Os dados qualitativos foram sistematizados a partir da análise de conteúdo inspirado em Bardin (2016). Para tanto, foram seguidas as três etapas fundamentais no processo de análise de conteúdo: a pré-análise, que consistiu na organização do material de pesquisa; a descrição analítica, momento em que o material organizado foi submetido a um estudo aprofundado tendo por base os referenciais teóricos da pesquisa; e a interpretação referencial, quando os elementos da investigação foram relacionados com as variáveis mais complexas como um todo e da totalidade social em que estavam inseridos, ou seja, a realidade dos/as formadas/os em Serviço Social, da Universidade Federal de Santa Maria.

Por fim, o material organizado buscou captar a realidade da formação profissional e sua relação com a educação continuada dessas/os assistentes sociais no contexto brasileiro. Pretendeu-se, como intencionalidade da pesquisa, aproximar-se da realidade das/dos assistentes sociais, buscando especificidades e análises com o propósito de produzir conhecimento científico sobre a temática proposta.

\section{Resultados}

O curso de Serviço Social da UFSM foi criado no ano de 2009, procedente do Programa de Apoio a Planos de Reestruturação e Expansão das Universidades Federais $(\text { REUNI) })^{5}$ e recebeu sua primeira turma em 2010/2. Trata-se, desse modo, de um curso recente, tendo em vista que conta com apenas cinco turmas formadas. Além disso, em 2013, conquistou um Departamento de Serviço Social (DSS). Atualmente, o quadro conta com 09 (nove) docentes e 04 (quatro) técnicos administrativos em educação, sendo desses, duas assistentes sociais e dois secretários, respectivamente do Curso de Serviço Social e do Departamento de Serviço Social da Universidade Federal de Santa Maria.

No Rio Grande do Sul, foi somente após 61 anos de história da área de Serviço Social que se conquistou o primeiro dos três cursos em Serviço Social em unidade de ensino federal, pública e gratuita. Assim, em 2006, foi inaugurado o Curso de Serviço Social, tutelado pela UFSM, em São Borja, fronteira oeste, interior do estado, hoje Universidade Federal do Pampa (Unipampa). O segundo curso foi fundado na capital gaúcha, Porto Alegre, em 2010/1, pela Universidade Federal do Rio Grande do Sul (UFRGS). E, em 2010/2, a UFSM inaugurou o

\footnotetext{
${ }^{5}$ Instituído pelo Decreto no 6.096, de 24 de abril de 2007 (BRASIL, 2007).
} 
terceiro curso de Serviço Social, agora na região central do estado, em Santa Maria, também no interior do Rio Grande do Sul.

Pela pesquisa documental realizada junto à secretaria do curso, em termos de contingente, o curso já havia formado 161 (cento e sessenta e um) ${ }^{6}$ bacharéis e bacharelas em Serviço Social até agosto de 2018. Sendo assim, enviou-se correspondência eletrônica com o questionário online convidando a totalidade de formados/as a participar da pesquisa. 0 retorno obtido foi de um total de 82 (oitenta e dois) respondentes, isto é, uma significativa adesão de mais de $50 \%$ do grupo. O Quadro 1 a seguir traça um panorama acerca do perfil desses/as egressas/os:

Quadro 1 - Perfil das/os egressos do curso de Serviço Social participantes da pesquisa.

\begin{tabular}{|c|c|}
\hline Variáveis & Indicadores \\
\hline Gênero & $\begin{array}{l}\text { - Masculino: } 18,3 \% \\
\text { - Feminino: } 81,7 \%\end{array}$ \\
\hline Idade & $\begin{array}{l}\text { - De } 21 \text { a } 25: 15,9 \% \\
\text { - De } 26 \text { a } 30: 37,8 \% \\
\text { - De } 31 \text { a } 35: 15,9 \% \\
\text { - De } 36 \text { a } 40: 13,4 \% \\
\text { - De } 41 \text { a } 45: 8,5 \% \\
\text { - Acima de } 46 \text { anos: } 8,5 \%\end{array}$ \\
\hline Orientação sexual & $\begin{array}{l}\text { - Heterossexual: } 89 \% \\
\text { - Homossexual: 6,1\% } \\
\text { - Bissexual: 4,9\% }\end{array}$ \\
\hline Estado Civil & $\begin{array}{l}\text { - Solteiro: } 53,7 \% \\
\text { - Casado: } 20,7 \% \\
\text { - União estável: } 22 \% \\
\text { - Divorciado: } 2 \% \\
\text { - Mora com companheiro: } 1 \%\end{array}$ \\
\hline Existência de filhas/os & $\begin{array}{l}\text { - Não: } 62,2 \% \\
\text { - Sim: } 37,8 \%\end{array}$ \\
\hline Raça/Cor & $\begin{array}{l}\text { - Branca: } 69,5 \% \\
\text { - Negra: } 8,5 \% \\
\text { - Parda: } 17,1 \% \\
\text { - Amarela: } 4,9 \%\end{array}$ \\
\hline Cidade natal & $\begin{array}{l}\text { - Santa Maria: 46,3\% } \\
\text { - São Pedro do Sul: 3,7 \% } \\
\text { - Agudo: 3,7\% } \\
\text { - Outras: } 46,3 \%\end{array}$ \\
\hline Cidade de Residência & $\begin{array}{l}\text { - Santa Maria: 58,5\% } \\
\text { - Porto Alegre: 6,1 \% } \\
\text { - Outras: } 35,4\end{array}$ \\
\hline Religião & - Católica: 40,2 \% \\
\hline
\end{tabular}

${ }^{6}$ Destes/as, um faleceu, permanecendo um total de 160 (cento e sessenta) profissionais. 


\begin{tabular}{|l|l|}
\hline & - Espírita: $18,3 \%$ \\
& - Evangélica: $13,4 \%$ \\
& - Agnóstico: $11 \%$ \\
& - Umbanda: $6,1 \%$ \\
& - Ateu: $4,9 \%$ \\
\hline Praticante de religião & - Sim: $60,6 \%$ \\
& - Não: $36,8 \%$ \\
\hline Ano de Ingresso & $-2010: 13,4 \%$ \\
& $-2011: 24,4 \%$ \\
& $-2012: 16,3 \%$ \\
& $-2013: 18,3 \%$ \\
& $-2014: 24,4 \%$ \\
\hline Motivo de escolha pelo Serviço Social & - Afinidade: $70,7 \%$ \\
& - Curso noturno: $26,8 \%$ \\
& - Por falta de opção melhor: $1,2 \%$ \\
\hline Total & - Influência familiar: $1,2 \%$ \\
\hline
\end{tabular}

Fonte: Elaborado pelas autoras (2019).

O perfil das/os participantes revelou que a identidade de gênero segue uma tendência histórica no Serviço Social, isto é, $81,7 \%$ identificaram-se como feminina e 18,3\% masculina; com idade predominante de 26 a 30 anos, 37,8\%, de 31 a 35 e de 21 a 25 anos, ambas com 15,9\%, dos 36 a 40 anos, 13,4\%, de 41 a 45, 8,5\% e acima de 46 anos, também com $8,5 \%$. A raça/cor que predominou foi branca em $69,5 \%$, parda em $17,1 \%$, negra em $8,5 \%$ e amarela em 4,9\%. A orientação sexual é, em sua maioria, heterossexual em $89 \%$, homossexual em $6,1 \%$ e bissexual em $4,9 \%$. O estado civil solteira/o em $53,7 \%$, união estável em $22 \%$, casada/o em $20,7 \%$, divorciado em $2 \%$ e mora com companheiro/a em $1 \%$ das respostas. Concernente à naturalidade, $46 \%$ informaram ser natural de Santa Maria e o restante de cidades diversas do estado. No momento da pesquisa, $58 \%$ das/os entrevistadas/os residiam em Santa Maria e 42\%, em outro município; 62\% não possuíam filhos e $38 \%$ possuíam.

Em termos comparativos, segundo a pesquisa "Assistentes sociais no Brasil: elementos para o estudo do perfil profissional" (CFESS, 2005) , realizada em 2004 pelo CFESS em convênio com a Universidade Federal de Alagoas, o perfil do/a assistente social brasileiro/a era de $97 \%$ mulheres, com apenas $3 \%$ de homens, as idades prevaleceram entre 35 a 44 anos em 38\%, 25 a 34 anos em 30\% e 45 a 59 anos em 25\%; de Religião Católica em 68\%, Protestante em 13\% e Espírita Kardecista em 10\% e nenhuma religião em $8 \%$ das respostas. A etnia foi de branca em $72 \%$ e negra em $2 \%$. 
Simões (2012) pesquisou as/os assistentes sociais brasileiras/os através da Pesquisa Nacional de Amostra por Domicílios (PNAD), assinalando a caracterização socioeconômica dessas/es profissionais com predominância feminina (95\%), média etária de 41 anos, cor branca, em sua maioria casadas, possuem filhas/os. Em termos de raça/cor, o estudo constatou ser de $66,1 \%$ branca, $27,1 \%$ parda e 5,5\% preta. "No entanto, a distribuição de cor/raça entre os assistentes sociais depende da região onde trabalham: o Sul é a região onde há o maior percentual de assistentes sociais brancos (91,3\%)" (SIMÕES, 2012, p. 134).

Mais recente, a pesquisa organizada pelo Departamento Sindical de Estatísticas e Estudos Socioeconômicos (DIEESE) e a Central Única dos Trabalhadores (CUT), com dados retirados da (MTE), intitulada "Quem são os assistentes sociais no Brasil?" (DIEESE; CUT, 2015), mostrou que, em 2013 , os/as assistentes sociais ocupados/as constituía-se de $78 \%$ de mulheres. A idade média desses/as era de 38,9 anos, sendo de 30 a 39 anos em $34 \%$. Sobre a etnia, observou-se um aumento significativo de negros/as comparando com a pesquisa realizada pelo CFESS, em 2004, o percentual, em 2013, era de $45 \%$ de negros/as.

$\mathrm{O}$ ano de ingresso das/dos assistentes sociais participantes da pesquisa realizada com as/os formadas/os pela UFSM chama a atenção pela representatividade das/os sujeitos oriundos de todas as turmas. Embora a primeira turma, de 2010, tenha tido uma participação menos expressiva $(13,4 \%)$, a segunda turma, de 2011 , teve uma significativa participação $(24,4 \%)$, a terceira turma, de 2012 , teve uma participação menos expressiva (16,3\%), a quarta turma, de 2013 , teve $18,3 \%$ de adesão e a quinta turma, de 2014 , também teve $24,4 \%$ de participação na pesquisa. Ressalta-se que essa é turma mais recente de formadas/os e que à época da pesquisa (maio de 2018), estavam a menos de seis meses de formadas/os. Esse dado é interessante também porque o estudo busca apreender a inserção no mercado de trabalho e/ou em processos de formação continuada, o que, para esse grupo de assistentes sociais, pode não ter tido tempo suficiente.

O motivo da escolha pelo Serviço Social também foi uma questão colocada as/aos participantes e, nesse sentido, $70,7 \%$ respondeu que foi por afinidade, contra $26,8 \%$ que respondeu que foi por ser um curso noturno, enquanto que para $1,2 \%$ foi por falta de uma opção melhor e, no mesmo percentual, por influência familiar. Ainda nesse sentido, vale compartilhar a opinião de uma/um egressa/o do curso que expôs no questionário sua satisfação em ter cursado Serviço Social: 
Sou uma pessoa mais feliz por ter conseguido acessar um curso de graduação noturno que me proporcionou uma formação de qualidade. Com isso, me tornei uma profissional em processo de busca constante pela formação permanente, pois o desejo e a necessidade de constante conhecimento estão mais acesos que nunca. (sic)

O depoimento dessa/e profissional impulsiona a acreditar no exercício profissional em Serviço Social e encoraja a busca por aprimoramento constante.

Quadro 2 - Inserção no mercado de trabalho, carga horária, rendimento mensal e/ou em cursos de formação continuada.

\begin{tabular}{|c|c|}
\hline Variáveis & Indicadores \\
\hline Inserção no mercado de trabalho & $\begin{array}{l}\text { - Sim: } 65,9 \% \\
\text { - Não: } 34,1 \%\end{array}$ \\
\hline Inserção na área de Serviço Social & $\begin{array}{l}\text { - Sim: } 42,7 \\
\text { - Não: } 57,3 \%\end{array}$ \\
\hline Carga horária semanal & $\begin{array}{l}\text { - } 40 \text { horas semanais ou mais: } 40 \% \\
\text { - Até } 30 \text { horas semanais: } 23,1 \% \\
\text { - Até } 20 \text { horas semanais: } 9,2 \% \\
\text { - } 60 \text { horas semanais: } 4,6 \% \\
\text { - Não estão trabalhando: } 13,6 \% \\
\text { - Demais horas: } 3 \%\end{array}$ \\
\hline Renda líquida & $\begin{array}{l}\text { - Um a dois salários mínimos: } 32,3 \% \\
\text { - Três a quatro salários mínimos: } 47,7 \% \\
\text { - Cinco a seis salários mínimos: } 3,1 \%\end{array}$ \\
\hline $\begin{array}{l}\text { Modo de inserção no mercado de trabalho } \\
\text { ou em cursos de formação continuada }\end{array}$ & $\begin{array}{l}\text { - Concurso público: } 27,7 \% \\
\text { - Celetista: } 16,9 \% \\
\text { - Contrato temporário: } 12,3 \% \\
\text { - Por indicação: } 9,2 \% \\
\text { - Residência Multiprofissional: } 10,5 \% \\
\text { - Autônomo: } 6 \%\end{array}$ \\
\hline Cursos de Formação Continuada & $\begin{array}{l}\text { - Especialização: 45,1\% } \\
\text { - Participação em eventos: 23,2\% } \\
\text { - Mestrado:7,3\% } \\
\text { - 4\%: não realizou nenhum }\end{array}$ \\
\hline
\end{tabular}

Fonte: Elaborado pelas autoras (2019).

O quadro 2 revela que, em relação à inserção no mercado de trabalho, a maioria, $66 \%$, referiu positivamente, enquanto que $34 \%$ não estava ainda inserida. Contudo, ao serem questionadas/os se estavam inseridos no Serviço Social, 57\% explicitaram que não, enquanto 43\% afirmaram estarem inseridas/os.

A carga horária predominante para quem estava inserida/o no mercado de trabalho foi de 40 horas semanais ou mais ( $40 \%)$, até 30 horas semanais $(23,1 \%)$, até 20 horas semanais $(9,2 \%)$, também referiram mais de 60 horas semanais (4,6\%) e outras horas não especificadas (3\%). Nesse sentido, fica evidente a inobservância da Lei no 12.317, de 26 de agosto de 2010 
(BRASIL, 2010) que acrescenta dispositivo à Lei № 8.662, de 07 de junho de 1993 (BRASIL, 1993), para dispor sobre a jornada de trabalho do assistente social brasileiro, pois determina que: "Art. 5 - A duração do trabalho do Assistente Social é de 30 (trinta) horas semanais." A mesma lei, no Art. 2으, estabelece ainda: "Aos profissionais com contrato de trabalho em vigor na data de publicação desta Lei é garantida a adequação da jornada de trabalho, vedada a redução do salário".

Outro indicativo de que a Lei $\mathrm{n} 012.317 / 2010$ ainda precisa ser efetivada refere-se à existência de alguns concursos públicos para assistente social que ainda solicitam, em seus editais, assistentes sociais para a jornada de 40 horas. Portanto, é imprescindível uma adequação de edital de concursos futuros em que seja respeitada a jornada de 30 horas, conforme a mencionada lei. Em que pese, inclusive, Nota de Esclarecimento do Conselho Federal de Serviço Social (CRESSRN, 2011), sobre a implantação da jornada de 30 horas para assistentes sociais sem redução salarial, ainda persiste a inobservância da sua aplicabilidade nos diversos espaços sócio-ocupacionais de atuação desses/as profissionais. Destarte, cabe não somente aos Conselhos Regionais fiscalizarem como também à categoria como um todo fazer as devidas denúncias para que essa conquista tão importante seja de fato aplicada.

Das/os assistentes sociais que se encontravam inseridos no mercado de trabalho, quando perguntados sobre a renda líquida em salários mínimos $(\mathrm{sm})^{7}, 48 \%$ responderam perceber de 3 a 4 sm, enquanto que 32\% referiam receber de 1 a $2 \mathrm{sm}$ e apenas $3 \%$ informaram receber um salário igual ou superior a 05 salários mínimos. Sobre a forma de inserção no mercado de trabalho ou nos estudos, teve destaque a questão do concurso público $(27 \%)$, celetista $(16,9 \%)$, contrato temporário/prestação de serviços $(12,3 \%)$, por indicação $(9,2 \%)$ e outras formas menos recorrentes, tais como pós-graduação e residência multiprofissional, essas últimas apesar de não serem admissão no mercado de trabalho, são inserções em cursos de formação continuada que permitem uma remuneração por meio de bolsa e, portanto, muitas vezes, são decisivas na sobrevivência das/dos assistentes sociais em determinado período de suas vidas.

Nesse sentido, é oportuno refletir sobre a intensificação da precarização das condições de trabalho dos/as trabalhadores/as resultante da Reforma Trabalhista de 2017 na qual a categoria de assistentes sociais não fica imune. Muito embora o objetivo deste artigo

\footnotetext{
${ }^{7}$ No ano de 2019, o salário mínimo da/o trabalhador/a brasileiro/a era de $\mathrm{R} \$ 998,00$.
} 
não seja o de analisar o impacto desta reforma na atual conjuntura brasileira e suas consequências para a inserção e a manutenção de assistentes sociais no mercado de trabalho, esse tema é relevante para outro estudo que paute exclusivamente tal questão. Além disso, não se pode negar que a Lei $n .0$ 13.467/17, aprovada como um elemento importante de uma agenda neoliberal, contribui ainda mais para a intensificação da superexploração e da precarização das condições de trabalho da classe trabalhadora brasileira, em benefício das grandes empresas capitalistas. (BRASIL, 2017).

Em tempos de crise e de ofensiva neoliberal, foi aprovada a reforma trabalhista (BRASIL, 2017), sob o pretexto de que havia uma extrema necessidade em abdicar das amarras do passado e renovar o Brasil, colocando na Consolidação das Leis do Trabalho (CLT) significativa culpa pelos entraves no desenvolvimento econômico do país. Conforme Monteiro et al. (2020, p. 117), "a Reforma Trabalhista trouxe significativas mudanças que suscitaram e suscitam críticas, gerando grandes incertezas para o futuro das(os) trabalhadoras(es)".

Além dessas incertezas para o futuro da classe trabalhadora brasileira, é importante lembrar que há uma orientação do governo Bolsonaro, desde a aprovação da reforma trabalhista, de que o mercado seja bastante flexibilizado, o que significa cada vez menos direitos às/aos trabalhadoras/es e mais mecanismos de exploração, situação essa preocupante ao público pesquisado, por isso a próxima questão pauta a formação continuada. A isso, $45,1 \%$ referiram estar cursando ou ter cursado especialização; $23 \%$ dizem ter participado de eventos; $7 \%$ Mestrado; $2 \%$ Doutorado e somente $4 \%$ afirmaram que não tinha realizado nenhum tipo de capacitação ou formação profissional continuada.

Apesar do exíguo tempo formadas/os, esses indicativos são particularmentes interessantes, tendo em vista o estudo de Simões (2012, p. 134), no qual afirma-se: “[...] 95,6\% dos assistentes sociais só possuem graduação, independente do ano e da região do país". Felizmente, esse indicativo de estagnação na formação profissional, após formação básica de graduação, indica estar mudando, tendo por base esses/as egressas/os da UFSM. 
Quadro 3 - Avaliação das/os egressas/os participantes da pesquisa sobre a formação em Serviço Social.

\begin{tabular}{|c|c|}
\hline Variáveis & Indicadores \\
\hline Avaliação da formação em SS & $\begin{array}{l}\text { - De qualidade satisfatória: } 58,5 \% \\
\text { - De excelente qualidade: } 37,8 \% \\
\text { - De qualidade a desejar: } 3,7 \%\end{array}$ \\
\hline $\begin{array}{l}\text { Relação entre sua formação } \\
\text { profissional em SS e sua } \\
\text { inserção, ou não, no trabalho }\end{array}$ & $\begin{array}{l}\text { - Diretamente relacionada: } 59,8 \% \\
\text { - Não está relacionada: } 18,3 \% \\
\text { - Um pouco relacionada: } 18,3 \% \\
\text { - Não sei responder: } 3,7 \%\end{array}$ \\
\hline $\begin{array}{l}\text { Qualidade do ensino em SS da } \\
\text { UFSM }\end{array}$ & $\begin{array}{l}\text { - De qualidade satisfatória: } 52,4 \% \\
\text { - De excelente qualidade: } 36,6 \% \\
\text { - De qualidade a desejar: } 11 \%\end{array}$ \\
\hline Corpo docente & $\begin{array}{l}\text { - De qualidade satisfatória: } 34,1 \% \\
\text { - De excelente qualidade: } 50 \% \\
\text { - De qualidade a desejar: } 13,4 \%\end{array}$ \\
\hline Disciplinas ofertadas & $\begin{array}{l}\text { - Muito importante para a sua formação profissional: } \\
53,7 \% \\
\text { - Importantes para a sua formação profissional: } 40,2 \%\end{array}$ \\
\hline $\begin{array}{l}\text { Após a formatura, a busca por } \\
\text { inserção profissional ou } \\
\text { formação continuada }\end{array}$ & $\begin{array}{l}\text { - Participei de concurso público somente na área de Serviço } \\
\text { Social: } 27,2 \% \\
\text { - Participei de seleções para cursos de Pós-Graduação } \\
\text { (Especializações, Mestrado): } 22,2 \% \\
\text { - Fui procurar trabalho na área de Serviço Social: } 16 \% \\
\text { - Participei de concursos públicos em qualquer área, } \\
\text { inclusive no Serviço Social: } 14,8 \% \\
\text {-Fui procurar trabalho em outra área que não fosse } \\
\text { relacionada ao Serviço Social: } 7,4 \%\end{array}$ \\
\hline $\begin{array}{l}\text { Maiores dificuldades no } \\
\text { mercado de trabalho no que } \\
\text { tange ao seu preparo } \\
\text { profissional em } \mathrm{SS}^{8}\end{array}$ & $\begin{array}{l}\text { - A qualidade de ensino que ficou a desejar: } 8,5 \% \\
\text { - A realidade de desemprego estrutural: } 59,8 \% \\
\text { - A retração do mercado de trabalho do AS: } 54,9 \%\end{array}$ \\
\hline $\begin{array}{l}\text { Fatores que contribuíram na } \\
\text { sua formação profissional de } \\
\text { assistente social }{ }^{9}\end{array}$ & $\begin{array}{l}\text { - Formação generalista, crítica e propositiva: } 76,8 \% \\
\text { - O meu esforço próprio: } 31,7 \% \\
\text { - Docentes qualificadas/os: } 41,5 \%\end{array}$ \\
\hline
\end{tabular}

Fonte: Elaborado pelas autoras (2019).

A avaliação da formação em Serviço Social por parte dos sujeitos do ensino é um retorno muito importante para o curso e para a Universidade em que esses se formaram, por

\footnotetext{
${ }^{8}$ Questão de múltipla escolha.

${ }^{9}$ Questão de múltipla escolha.
} 
isso, uma das questões centrais que foi considerada no questionário foi justamente a respeito de como esses percebiam a sua formação, sendo que, para $58,5 \%$, foi de qualidade satisfatória; para $37,8 \%$ de excelente qualidade e somente $3,7 \%$ consideraram que a qualidade ficou a desejar.

No que tange à qualidade do ensino em Serviço Social, foi avaliada com qualidade satisfatória, segundo $58,5 \%$, e de excelente qualidade para $37,8 \%$ das/dos assistentes sociais participantes. De acordo 59,8\% das/os assistentes sociais participantes da pesquisa, estava diretamente relacionada a sua formação profissional e sua inserção ou não no trabalho, enquanto que $18,3 \%$ estava um pouco relacionada e, também para $18,3 \%$, não existia relação entre a formação profissional e sua inserção ou não no trabalho.

Sabe-se que estar preparada/o para o mercado de trabalho é essencial para obtenção do sucesso na carreira. Esse preparo está associado à satisfação das/dos egressas/os na qualidade da formação e do ensino de graduação, sobre o segundo, 52,4\% referiram que foi de qualidade satisfatória, $36,6 \%$ de excelente qualidade e somente $11 \%$ avaliaram que a qualidade de ensino deixou a desejar.

A avaliação sobre o corpo docente foi avaliada de forma positiva pelas/os sujeitas/os da pesquisa no que diz respeito ao curso de Serviço Social da UFSM. Nesse sentido, na opinião de $50 \%$ das/dos participantes, o corpo docente que compôs o curso de Serviço Social da UFSM foi de excelente qualidade, $34,1 \%$ consideraram de qualidade satisfatória e 13,4\% referiram que a qualidade do corpo docente deixou a desejar.

Após a formatura, as/os assistentes sociais participantes da pesquisa percorreram caminhos diversos, seja na busca por inserção no mercado de trabalho, seja na busca por qualificação profissional. Sendo assim, a participação em concurso público somente na área de Serviço Social foi uma alternativa para 27,2\%; a participação de seleções para cursos de pós-Graduação (especializações, mestrado) foi de 22,2\%; a procura por trabalho na área de Serviço Social foi de 16\%; participação de concursos públicos em qualquer área, inclusive no Serviço Social foi de $14,8 \%$ e a procura por trabalho em outra área que não fosse relacionada ao Serviço Social foi de $7,4 \%$.

Os dados evidenciam que, após a formatura, as/os assistentes sociais foram à luta por espaços diversos, principalmente relacionadas a sua área de formação profissional. Os depoimentos a seguir enfatizam essa busca: "[...] quando estava perto do processo de formatura, de colar grau, eu já fiquei muito angustiada porque a gente se forma, tem uma 
pretensão de carreira e eu fiquei pensando o que fazer, quais seriam os próximos passos" (Entrevista 3). O depoimento a seguir evidencia o quanto a busca por conhecimento continua após a formatura: "Não fiquei sem estudar [...]" (Entrevista 1).

De acordo com as/os assistentes sociais participantes, os fatores que mais contribuíram na sua formação profissional foram a formação generalista, crítica e propositiva $(76,8 \%)$, docentes qualificadas/os (41,5\%) e o esforço próprio $(31,7 \%)$. Ressalta-se que esta foi uma questão de múltipla escolha.

A formação continuada é uma exigência atual aos profissionais que desejam se inserir e permanecer em sua área, em que consiste estar, conforme abordam Pinto, Barreiro e Silveira (2010, p. 3) "associada à atualização, a continuidade da formação profissional tem sido entendida como uma exigência a acompanhar a vida dos indivíduos em todas as áreas do conhecimento".

Nessa perspectiva, a formação continuada abrange todas as iniciativas de formação feitas após a graduação. As/os sujeitas/os da pesquisa, ao serem questionados sobre a formação continuada, no que ela pode contribuir na atuação do assistente social, trouxeram vários aspectos instigantes à reflexão:

[..] a gente precisa estar sempre estudando, mudando, estar sempre se atualizando, eu ainda continuo essa caminhada de seguir, quero continuar estudando também e estar sempre me aperfeiçoando. (Entrevista 1)

Essa pesquisa também é muito importante para a gente estar qualificando o curso de serviço social, é importante também pesquisar como estão os cursos de serviço Social que a gente sabe que tem uma elevada, crescente número de EaD [Educação a Distância], aparecendo e como que estão as universidades públicas, qual a qualidade de ensino que estão dando para os alunos? Toda vez que a gente produz conhecimento, produz índices, podemos barganhar e pedir políticas públicas, pedir investimentos... porque toda vez que a gente tem dados para demonstrar a importância das coisas, se consegue muito mais avanços. E se a gente nunca se pergunta como estão as coisas, vão ficar sempre do mesmo jeito. É através das pesquisas que as coisas melhoram, tem avanços na Política de educação permanente do CFESS/CRESS (Entrevista 3).

Fica evidente, nos depoimentos acima, a inquietação das/os participantes da pesquisa em continuar a busca de novos estudos, de aprendizados para fortalecer a/o profissional e sua atuação, coerente com o que apregoa um dos princípios do Código de Ética do Assistente Social, voltado ao compromisso com a qualidade dos serviços prestados à população usuária e com o aprimoramento intelectual, na perspectiva da competência profissional (CFESS, 2011). Por isso, logo foram questionados/as se conheciam a Política de 
Educação Permanente do CFESS/CRESS e o que pensavam a respeito. Aas/os assistentes sociais trouxeram questões instigantes para pensá-la e divulgá-la, conforme pode ser observado nos fragmentos a seguir:

Não tenho muito o que dizer porque eu não me aprofundei sobre o estudo [..]. Mas acho que sim, vem num processo de políticas e algumas coisas para aprimorar e para acrescentar, sim, na base. (Entrevista 1)

[...] já ouvi falar, talvez em meios de discussão, mas, por vontade minha porque a gente tem todas as ferramentas para buscar o que quiser [...]". (Entrevista 2)

A política de educação permanente tem muito a contribuir porque o profissional tem que estar sempre se movimentando, sempre procurando, estar em aprendizado, estar se aperfeiçoando porque o conhecimento nunca para, e mesmo que a gente tenha feito graduação, mestrado, doutorado, o conhecimento sempre se aprofunda, as coisas sempre se modificam. Então a educação permanente, eu vejo isso, a pessoa sempre se reatualizando na sua prática e isso traz benefícios tanto para o profissional que não se angustia com as coisas que vão acontecendo, quanto para o campo de prática, que sempre está sendo renovado, práticas cada vez mais humanizadas, desburocratizadas. (Entrevista 3)

Deveria ter mais visibilidade e ser mais efetivada a questão da educação permanente. Tanto nesses espaços de graduação, quanto nos espaços, por exemplo do NUCRESS, das reuniões, que a gente tem feito isso, tem discutido algumas questões, bem nessa lógica de educação permanente, até para incentivar os profissionais. (Entrevista 5)

Pelas entrevistas realizadas com as/os profissionais, é possível depreender que, mesmo não conhecendo profundamente a Política de Educação Permanente do conjunto CFESS/CRESS, as/os assistentes sociais entrevistadas/os também demonstraram não a ignorar, trazendo pontos importantes para o debate da categoria, especialmente ao fato de que essa política deveria ter mais visibilidade.

As maiores dificuldades que foram identificadas no mercado de trabalho referente ao preparo profissional em Serviço Social estavam relacionadas, em $59,8 \%$, à realidade do desemprego estrutural e, em $54,9 \%$, à retração do mercado de trabalho de assistentes sociais, enquanto que $8,5 \%$ atribuíram a qualidade de ensino que ficou a desejar. Isso é perceptível no excerto da entrevista realizada com as/os assistentes sociais: "As vagas que estão cada vez menores, o número de vagas de assistentes sociais, o salário... a gente percebe que [...] o valor do salário é muito baixo em relação ao que a gente imagina ou se organiza" (Entrevista 1).

As condições de trabalho da/do assistente social, mais especificamente no que se refere à remuneração, conforme a Entrevista1, muitas vezes não condiz com a formação em ensino superior exigida para a função, além de as vagas serem escassas, há poucos concursos 
e, esses, na maioria das vezes, ofertam salários baixos com carga horária além da permitida pela Lei no 12.317/2010, conforme mencionado anteriormente.

Além disso, Faermann e Mello (2016) discutem as condições de trabalho dos assistentes sociais e suas implicações no processo de adoecimento dos profissionais, ressaltando que o trabalho e o adoecimento no Serviço Social têm como eixo norteador o contexto da crise contemporânea do capital e as novas formas de precarização e intensificação do trabalho. Muito embora, o estudo ter sido publicado em 2016, em um contexto um pouco mais ameno que esta pesquisa, as reflexões apresentadas permitem identificar fatores presentes no exercício profissional que desencadeiam processos de sofrimento e de adoecimento. Os resultados mostram que, diante de um contexto de profundas transformações marcado pelo acirramento da questão social, pelo ataque aos direitos trabalhistas, pela retração e desregulamentação do trabalho, os problemas decorrentes desse processo são acentuados.

[...] problematizar o trabalho do assistente social na atualidade supõe pensá-lo como alíquota do trabalho da classe trabalhadora, que vende sua força de trabalho em troca de um salário, sujeito às violações e aos constrangimentos comuns a todos os trabalhadores assalariados. É nesse contexto que a discussão do sofrimento e do adoecimento vem ocupando centralidade no Serviço Social, em decorrência do processo brutal de mercantilização da força de trabalho do assistente social na sociedade contemporânea. (FAERMANN; MELLO, 2016, p. 99)

A inserção no mercado de trabalho deveria ser motivo de realização e objetivação da/do assistente social, o fundamento essencial resultante de uma formação de qualidade, além do aspecto necessário da sobrevivência. Contudo, a sociedade capitalista explora ao máximo essa força de trabalho fazendo com que, muitas vezes, o trabalho se traduza em sofrimento e adoecimento.

\section{Considerações Finais}

De maneira geral, constatou-se que a maioria das/os formadas/os estava inserida no mercado de trabalho, predominantemente fora de sua área de formação, embora também apareceu um significativo percentual atuando como assistente social. Entretanto, a baixa remuneração ofertada, como também o descumprimento da Lei $n$ N 12.317/2010 que dispõe sobre a Jornada de trabalho e remuneração dos/as Assistentes Sociais, foi uma das constatações importantes desta pesquisa. A referida Lei acrescenta dispositivo à Lei no 8.662 / 
1993, para dispor sobre a duração do trabalho do assistente social brasileiro sendo esse de no máximo 30 horas semanais. Tratando-se essa de uma ação política do CFESS na luta pela efetivação das 30 horas semanais, assim como o indicativo de remuneração aos/as profissionais, exigida aos/as assistentes sociais foram consideradas como uma das características dessa inserção profissional.

Em contrapartida, foram percebidos como facilitadores deste processo a realização de atividades de formação continuada em Serviço Social, com destaque para cursos de especialização (especialmente a Residência Multiprofissional em Saúde) e/ou de mestrado e até mesmo o doutorado. As evidências encontradas na pesquisa podem fornecer indicadores acerca da qualidade do ensino em Serviço Social da UFSM, bem como contribuir para o aprimoramento contínuo da formação inicial oferecida aos estudantes de Serviço Social.

Por fim, é mister enfatizar que a formação na graduação é um importante suporte que será um marco ao longo da trajetória profissional, contudo esta não é suficiente para toda atuação, em todos os campos que é possível o trabalho da/do assistente social. Sendo assim, é imprescindível uma busca infinita por aprimoramento nos campos almejados pela/o assistente social.

\section{Referências}

BARBETTA, Pedro Alberto. Estatística aplicada às ciências sociais. 6. ed. Florianópolis: UFSC, 2006.

BARDIN, Laurence. Análise de conteúdo. Tradução de Luiz Antero Reto e Augusto Pinheiro. Lisboa: Edições 70, 2016.

BRASIL. Decreto no 6.096, de 24 de abril de 2007. Institui o Programa de Apoio a Planos de Reestruturação e Expansão das Universidades Federais - REUNI. Brasília, DF: Presidência da República, 2007. Disponível em: http://www.planalto.gov.br/ccivil_03/_ato20072010/2007/decreto/d6096.htm. Acesso em: 9 jan. 2017.

BRASIL. Lei no 12.317, de 26 de agosto de 2010. Acrescenta dispositivo à Lei $n=8.662$, de 07 de junho de 1993, para dispor sobre a duração do trabalho do assistente social brasileiro. Brasília, DF: Presidência da República, 2010. Disponível em: http://www.planalto.gov.br/ccivil_03/_Ato2007-2010/2010/Lei/L12317.htm. Acesso em 15 jan. 2020.

BRASIL. Lei no 13.467, de 13 de julho de 2017. Altera a Consolidação das Leis do Trabalho (CLT), aprovada pelo Decreto-Lei $n=5.452$, de 1ㅇ de maio de 1943, e as Leis $n \circ 6.019$, de 3 de janeiro de 1974, 8.036, de 11 de maio de 1990, e 8.212, de 24 de julho de 1991, a fim de adequar a legislação às novas relações de trabalho. Brasília, DF: Presidência da República, 
2017. Disponível em: http://www.planalto.gov.br/ccivil_03/_ato20152018/2017/lei/l13467.htm. Acesso em: 15 jan. 2020.

BRASIL. Lei no 13.935, de 11 de dezembro de 2019. Dispõe sobre a prestação de serviços de psicologia e de serviço social nas redes públicas de educação básica. Brasília, DF: Presidência da República, 2019. Disponível em: http://www.in.gov.br/en/web/dou/-/lei-n-13.935-de-11-dedezembro-de-2019-232942408. Acesso em: 21 dez. 2019.

BRASIL. Lei no. 8.662/9, de 7 de junho de 1993. Dispõe sobre a profissão de Assistente Social e dá outras providências. Brasília, DF: Presidência da República, 1993. Disponível em: http://www.planalto.gov.br/ccivil_03/leis/l8662.htm\#: :text=LEI\%20No\%208.662\%2C\%20DE (Mensagem\%20de\%20veto).\&text=0\%20PRESIDENTE\%20DA\%20REP\%C3\%9ABLICA\%20Fa\% C3\%A7o,eu\%20sanciono\%20a\%20seguinte\%20lei\%3A\&text=1\%C2\%BA\%20\%C3\%89\%20livre \%20o\%20exerc\%C3\%ADcio,as\%20condi\%C3\%A7\%C3\%B5es\%20estabelecidas\%20nesta\%20le i. Acesso em: 28 set. 2020.

CFESS. Conselho Federal de Serviço Social. (Org.). Assistentes sociais no Brasil: elementos para o estudo do perfil profissional. Brasília: CFESS, 2005.

CFESS. Conselho Federal de Serviço Social. Código de ética profissional dos assistentes sociais. 9. ed. Brasília, DF: CFESS, 2011.

CFESS. Conselho Federal de Serviço Social. Política de educação permanente do conjunto CFESS-CRESS. Brasília-DF: CFESS, 2012. Disponível em:

http://www.cfess.org.br/arquivos/BROCHURACFESS_POL-EDUCACAO-PERMANENTE.pdf. Acesso em: 18 nov. 2018.

CFESS. Conselho Federal de Serviço Social. Sem serviço social no INSS, quem perde é você! sabe por quê? Brasília: CFESS, 2019. Disponível em:

http://www.cfess.org.br/visualizar/noticia/cod/1639. Acesso em: 10 jan. 2020.

CRESSRN. Conselho Regional de Serviço Social do RN. Esclarecimento sobre a implantação da jornada de 30 horas para assistentes sociais sem redução salarial. Mossoró: CRESSRN, 2011. Disponível em:

http://www.cressrn.org.br/app/webroot/upload/files/manifestacaocfess30horas.pdf. Acesso em: 28 set. 2020.

DIANNI, Claudia. MP do Programa Verde Amarelo extingue serviço social do INSS. Correio Brasiliense, Brasília, 21 nov. 2019. Disponível em:

https://www.correiobraziliense.com.br/app/noticia/economia/2019/11/21/internas_econo mia,807942/mp-do-programa-verde-amarelo-extingue-servico-social-do-inss.shtml. Acesso em: 12 jan. 2020.

DIEESE. Departamento Intersindical de Estatísticas e Estudos Socioeconômicos; CUT. Central Única dos Trabalhadores. "Quem são os assistentes sociais no Brasil?" Brasília: DIEESE: CUT, 2015. Disponível em: http://www.fenas.org.br/documentos.aspx?t=P. Acesso em: 10 jan. 2016.

FAERMANN, Lindamar Alves; MELLO, Cássia Camila Val. As condições de trabalho dos assistentes sociais e suas implicações no processo de adoecimento dos profissionais. Textos 
\& Contextos, Porto Alegre, v. 15, n. 1, p. 96-113, jan./jul. 2016. doi: 10.15448/16779509.2016.1.23035. Disponível em:

https://revistaseletronicas.pucrs.br/ojs/index.php/fass/article/view/23035. Acesso em: 28 set. 2020.

FRAGA, Cristina Kologeski. A atitude investigativa no trabalho do assistente social. Serviço Social \& Sociedade, São Paulo, n. 101, p. 40-64, jan./mar. 2010. doi: 10.1590/S010166282010000100004. Disponível em: https://www.scielo.br/pdf/sssoc/n101/04.pdf. Acesso em: 29 dez. 2019.

GIL, Antonio Carlos. Como elaborar projetos de pesquisa. 4. ed. São Paulo: Atlas, 2007.

MINAYO, Maria Cecília de Souza. O desafio da pesquisa social. In: MINAYO, Maria Cecília de Souza (org.). Pesquisa social: teoria, método e criatividade. 32. ed. Rio de Janeiro: Vozes, 2012. p. 9-29.

MONTEIRO, Fernando; FORTUNA, Sandra Lourenço de Andrade; NASCIMENTO, Silmara Aparecida; PATRIARCHA, Taynara Fitz. A reforma trabalhista e a precarização dos direitos das mulheres negras no Brasil. Sociedade em Debate, Pelotas, v. 26, n. 2, p. 115-126, maio/ago. 2020. Disponível em: http://revistas.ucpel.edu.br/index.php/rsd/article/view/2619/1678. Acesso em: 27 set. 2020.

PINTO, Carmem Lúcia Lascano; BARREIRO, Cristhianny Bento; SILVEIRA, Denise Nascimento. Formação continuada de professores: ampliando a compreensão aceca deste conceito. Revista Thema, Pelotas, v. 7, n. 1, p. 1-14, 2010. Disponível em: http://revistathema.ifsul.edu.br/index.php/thema/article/download/19/19. Acesso em 29 dez. 2019.

PRATES, Jane Cruz. O método marxiano de investigação e o enfoque misto na pesquisa social: uma relação necessária. Textos \& Contextos, Porto Alegre, v. 11, n. 1, p. 116-128, jan./jul. 2012. doi: 10.15448/1677-9509.2019.2. Disponível em:

http://repositorio.pucrs.br/dspace/bitstream/10923/7985/2/O_metodo_marxiano_de_inve stigacao_e_o_enfoque_misto_na_pesquisa_social_uma_relacao_necessaria.pdf. Acesso em: 8 jul. 2018.

SIMÕES, Pedro. Assistentes sociais no Brasil: um estudo a partir das Pnads. Rio de Janeiro: Epapers, 2012. 